\title{
Headlines and Head-space: Challenging Gender Planning Orthodoxy in Area- based Urban Development
}

\author{
Jo Beall and Alison Todes*
}

\section{Introduction}

Gender planning orthodoxy holds that an explicit gender focus needs to be maintained in the formulation, design and implementation of development programmes and projects. This has given rise to calls to mainstream gender in development (Jahan 1995) and to institutionalise gender competency in development planning (Levy 1996). Some have gone so far as to make the argument for the 'development of gender planning as a separate planning tradition in its own right' (Moser 1993: 1). Others have been satisfied with a more generalised trend to foster gender sensitivity in existing development policy and practice (Beall 1998; Goetz 1997). Whatever the starting point, the gender and development industry has spawned a proliferation of competing frameworks designed to guide gender integrated development interventions. Critics have questioned whether these different frameworks are grounded in feminist theory (Kabeer 1994) or are simply instrumentalist (Jackson and Pearson 1998)

Drawing on the experience of a highly acclaimed area-based urban development initiative in Cato Manor, Durban, we ask whether in the context of the favourable political conditions such as those that prevailed in South Africa during the first postapartheid decade, rendered unnecessary an explicit gender planning focus at project level. In its design and documentation, the Cato Manor Development Project (CMDP) was largely devoid of the compulsory "headlines" and "headcounts" of gender planning, against which progress on gender awareness and women's participation are usually measured. Nevertheless, during implementation, the Cato Manor Development Association (CMDA) paid significant attention to gender relations and women's involvement. To explain this, we argue for the importance of understanding history and the legacy of women's organisation, as well as the impact of higher level policy on gender. With this in place, we show how the efforts of politicised women at community level and the support of social justice advocates working within project structures rendered insignificant the lack of an explicit gender planning focus and allowed for the emergence of a gender "head-space" among the practitioners and partners involved. As such, we argue that gender planning is not the only way in which development initiatives can bring positive change to the conditions of women's lives and lead to the transformation of gender relations. Indeed, we show that even when a gender focus did begin to inform the Cato Manor initiative, it was made more effective by the historical legacy of women's struggles in Cato Manor and the political and policy conditions in post-apartheid South Africa.

\section{History of Cato Manor}

Situated only some $7 \mathrm{~km}$ from Durban's city centre, Cato Manor has been a highly contested part of the city for many years. In the post-war period it housed thousands of African tenants who rented accommodation from the Indian landlords who owned homes in Cato Manor before the area was proclaimed "white" in terms of apartheid legislation in 1963. Following the forced removals of Indians and Africans in the 1960s, the land laid dormant for many years. This situation prevailed until squatters invaded the area in the late 1980s (Makhathini 1992; Hindson and Byerley 1993), at a time when the legitimacy of apartheid institutions 
was under concerted political attack from those within the national liberation movement.

The historical record pays considerable attention to the role of women in Cato Manor's history. In the post-war years many sustained themselves through beer brewing and by so doing, resisted the infamous "Durban System" whereby the municipality paid for the maintenance of African townships through profits from their monopoly on African beer. In addition, the women of Cato Manor were vocal and visible in their opposition to the infamous pass laws in the 1950s, as well as to the removals to the townships of KwaMashu and Umlazi in the 1960s (Maylam 1996: 24). Dorothy Nyembe, a key activist in Cato Manor, became recognised nationally as a political leader and the role of the African National Congress Women's League (ANCWL) was significant in the struggles of the 1950s and 1960s. Hence, Cato Manor was known as an important island of women's resistance during the dark days of apartheid (Edwards 1996: 102). In the contemporary period we found that this history of women's resistance was evoked in justification of women's involvement in land evasions in Cato Manor and later to rally women into organising towards development in the area.

\section{The Cato Manor Development Project}

With the end of apartheid in sight in 1990 a multistakeholder body known as the Greater Cato Manor Development Forum (GCMDF) was formed. It sought to develop consensus between different parties through the formulation of an integrated planning framework for the area. The plan envisaged Cato Manor as a model for post-apartheid development: a socially mixed area offering housing, employment and facilities in a well-located residential part of the city, which reversed the legacy of apartheid segregation. However, conditions did not favour mould-breaking development strategies. Local government was caught in a period of considerable political uncertainty and suspicious government bodies, threatened by the project, were unwilling to cede control. The CMDA did not anticipate having to deal with land claims from former Indian and African residents and in addition to competing land claims, they confronted a conservative and reactive white population on its borders. Within Cato Manor itself, problems came in waves. The area development plan was conceived and initiated without sufficient engagement with communities or understanding of the settlement dynamics in the area. This proved to be a source of tension in later years. Moreover, successive land invasions, rising crime and violence, alongside complex and shifting local politics meant that the early years of the CMDA were preoccupied with simply establishing the conditions for an areabased development project to proceed at all (Hindson et al. 2002).

Squatters started moving into Cato Manor from the late 1980s. As South Africa moved closer to a political settlement their numbers swelled through a series of land invasions, so that by 1994 the population had increased from around 3,000 to 14,868. Although some were no doubt opportunistic, keen to get a foothold in this prime location close to the city, most came to escape political tensions elsewhere and most had some direct or indirect experience of violence in their areas of previous settlement (Makhathini 1992: 2). They were predominantly young, single and unemployed, with nearly half being women household heads (48 per cent) and many moving to the area after the death of their husbands (Makhathini and Xaba 1995). Important for subsequent community politics in Cato Manor is that women were at the heart of these land invasions.

An important part of the history of Cato Manor is the fact that by the mid-1990s crime and violence had become major problems, only in part linked to earlier patterns of political violence. At its height, much of the conflict was attributed to wars between rival groups of taxi-owners who were contesting lucrative new commuter routes, as well as gang violence between groups of unemployed youths. The gender dimensions of the conflict were highlighted by a dramatic rise in teenage pregnancies and a significant increase in rape during this time. Petersen et al. (2003) show that the extent of social fragmentation and disintegration in the area, in part associated with the high proportion of people displaced by violence, has resulted in a generalised social ethos of distrust, isolation and social fragmentation. These conditions have been associated with higher levels of rape than elsewhere in the province, and with higher rates of HIV/AIDS.

The fluid and socially fragmented nature of the area militated against collective action. Nevertheless, an engaged if not inclusive civil society emerged in Cato Manor. It was infused with political agendas and driven by strong leaders, not all of whom 
operated in the public good. Powerful women were among them, exerting pressure towards their own ends as much as for the development interests of the residents they represented. Against this difficult background the CMDA has managed in its decadelong existence to make some incredible strides on behalf of both women and men in Cato Manor. The next section reviews some of the project's achievements in relation to gender issues.

\section{Gender achievements in the Cato Manor Development Project}

The CMDP was established in 1993 and in the year following the first democratic elections in 1994 became a presidential lead project under the Reconstruction and Development Programme (RDP). For much of its ten-year lifespan, vast resources were ploughed into the project both by government and donors, notably the European Union (EU). The CMDA was set up as a specialist agency to oversee the initiative, with a fair degree of autonomy. As such it could be innovative and flexible in its approach. Indeed, operational agility is a hallmark of area-based initiatives, alongside concentrated effort and integrated approaches and certainly was a key characteristic of the CMDA until it was dismantled at the end of the project in 2002.

The CMDP took root in the early to mid-1990s at a time when the so-called "national machinery" for advancing gender equality in South Africa was being developed, when non-sexism was being enshrined in the new South African constitution and when the ANCWL had won a one-third quota in the African National Congress (ANC). Consequently issues of women's participation and gender equity were common currency and being robustly asserted. Strong support for gender integration was also evident from within the RDP and the EU. Despite all these factors, the CMDP was designed without any reference to a gender perspective, which was absent from project documents, project research and the collection of data used to monitor the performance of the project. This made later analysis along gender lines a laborious process (Beall et al. 2002).

One factor explaining this was the difficult environment facing the CMDA and the fact that only in the late 1990s was it able to move from crisis management to delivery. From 1997 to 2000 there was an emphasis on physical development, reflecting a concern to respond to the massive delays in project start up, as well as the tremendous backlogs in basic infrastructure and services in the area. The focus on the provision of basic infrastructure, housing, roads, schools and social facilities was a further factor explaining the absence of a gender perspective. Indeed, the contested nature of the project and the emphasis on getting it underway after a difficult start meant that social analysis in general was neglected.

Nevertheless, even in the first phase of delivery there was an evolving recognition of the need for a better understanding of social and indeed gender dynamics in the area. The growing awareness of gender among CMDA staff took a particular form. First, there was an implicit view that women constituted the stable base of the community and should be the focus of development initiatives. This stereotype of women as reliable partners is common in development practice and leads to an instrumental use of women for development purposes. This was arguably the case with the CMDA, fearing project failure if it were left to men who were considered transient, unreliable and potentially irresponsible. Nevertheless, CMDA practice was not far from that advocated in the gender planning literature, where women are presented as useful in their role as community managers (Moser 1987, 1993).

Moreover, the CMDA delivered outputs that addressed women's concerns, with respect to land, housing, services and settlement planning. Cato Manor was planned for full services (waterborne sewerage, piped inside water supply, electricity connections) all of which brought enormous benefits to women in terms of their domestic responsibilities, beyond more generalised environmental health and poverty reduction benefits. The layout of local residential areas and other aspects of design occurred on the basis of inclusive consultation. Social facilities such as sports fields and community centres were provided with the goal of accommodating the recreational needs of different groups and concerns about women and children's safety were paramount in spatial planning. For example, issues such as street lighting were taken seriously and attention was paid to the design of parks and public buildings.

The proportion of women household heads now owning homes in Cato Manor is impressive. Among the higher income group buying mortgaged housing, some 45 per cent of owners are women 
with 12 per cent in joint ownership. Among the low-income groups half of all houses built went to women. Women community representatives were keen to ensure that title deeds were held in the name of women. People interviewed cited cases where a man's partner and children had been thrown out by his relatives after he had died of AIDS, or where men had found new lovers and evicted their previous partners from their homes. These concerns were taken seriously by the CMDA who made a concerted effort to understand who was the actual functional head of a household and who was responsible for the children. Taking seriously the issue of women's security of tenure led to a broader awareness of gender power relations and a desire to avoid outcomes that served to marginalise women and children from the benefits of the project.

One of the housing projects within Cato Manor, which is run by an NGO, in fact directly targeted women. This social housing project swiftly exceeded by 17 per cent its target of housing 45 per cent of women-headed households. A particular innovation was a lease agreement that gave tenure rights to all members of a household at the time of signing. It also provided for the children of deceased leaseholders to continue living in the unit, protecting in turn their rights to secure tenure. Workshops were conducted around the lease agreement to ensure that there was clear understanding of its implications, including role-playing of possible situations a leaseholder might encounter, including domestic violence. A perverse outcome of the project was that the high concentration of young women and children in a single housing project attracted the attention of men. Moreover, a disproportionately high concentration of young women residents engaged in sex work. This is something for which the project designers were not prepared and over which they felt powerless to act.

In the later phase of the project social and economic projects were introduced, significantly extending the ways in which women were able to benefit from the project. An effective initiative was the Crime Prevention Strategy designed to respond to the high levels of crime and warlordism in the area. Women played a key role in developing this strategy through their informal networks and presence in the community. Although crime is still a concern, levels of violent crime have been drastically reduced. However, gender-based violence remains, with high levels of rape and domestic violence in a context of high prevalence of HIV/AIDS. Contrary to gender stereotypes though, some women were themselves involved in violence and warlordism, with many being key players in informal land and housing markets. Two projects initiated in the later stages included important empowerment dimensions for women. These were Economic Life Skills, which provided training in basic economic knowledge and the Home Ownership Education project, which looked at the challenges of home ownership and affordability. Both, which attracted mostly women, became a forum in which gender issues such as inheritance practices were discussed. A gender activist who was keenly alert to gender issues ran the courses and they were a very successful gender intervention although the exclusion of men, even if on a selfselection basis, may be as damaging as the exclusion of women in the long run.

However, men were the main beneficiaries from the CMDA's local economic development programme, which saw them involved in enterprises at the higher levels, including the development of industrial and retail parks and tourism promotion. Women, by contrast, were concentrated in projects at the bottom end although they do seem to have benefited from some of the projects aimed at training and support of small businesses. A cooperative programme was also developed, working with savings clubs in order to strengthen the social economy and this mostly involved women. They were assisted in improving business skills and the viability of their operations and cooperatives were developed in urban agriculture, commercial cleaning, crafts, block-making, chemicals production, cultural pursuits, training, health care, and traditional medicine. For the most part, the CMDA avoided traditional women's activities, such as sewing, where it was difficult to compete with established markets. Nevertheless, many cooperative activities just helped women to survive, rather than providing them with a secure business future; better than nothing one might argue, given the high levels of unemployment and the fact that men had cornered most of the job opportunities. In terms of job creation, although about half of the trainees in vocational programmes were women and despite perceptions in the CMDA that job placement programmes have largely benefited women, in fact some 92 per cent of jobs, mainly in construction, were taken up by men. 
When reviewed as a whole the CMDA was gender sensitive to quite an extraordinary degree. During the first phase of implementation, with its primary focus on physical development, the project afforded an impressive number of women and women-headed houses. As the project stabilised and as an integrated area-based development focus was reasserted, the shift from a focus purely on physical development saw a greater emphasis on economic and social development. This led to more specific consideration of gender issues within programme activities. Ironically, it was in the first phase that the strategic issues of women's property rights and personal safety were directly addressed. In the later phase, social and economic development projects were concerned with women's livelihood issues and tended to reinforce rather than challenge customary gender divisions of labour. Empowerment projects were the exception, focusing as they did on home ownership and inheritance, alongside the concerns of ordinary women.

\section{Politics, organisation and gender in Cato Manor}

The multiplicity of moral claims on Cato Manor meant that political life was bound to be fraught and highly contested during the ten years of the CMDA's involvement in the area. Leadership structures were fluid and fragile in the early years and some experienced a level of criminality. This made it difficult for the CMDA, who in turn were feeling their way in terms of their commitment to participatory development. There was competition between squatters' organisations and the more established civic organisations in the former township areas incorporated into the CMDP. Some were quite formal in their operations and closely linked to the ANC at the local level. Others were more casual and cavalier. The associations of taxiowners and shacklords were often destructive in their engagement with the CMDA, while youth gangs such as the $\mathrm{MK}^{1}$ Reaction Unit, made consultation and participatory processes well nigh impossible.

Women leaders were particularly adept at negotiating this organisational terrain and gained enhanced credence with the CMDA. Their legitimacy among many supporters derived from a long history of involvement in land invasions, community organisation and progressive politics. However, this support was not universal and the heavy-arm tactics on the part of some raised concern among both male and female residents of Cato Manor. Not averse to carrying weapons themselves, some were as strident as any male leaders in the area and faced similarly rough treatment. Recently and after the closure of the CMDA, one of the women leaders was shot by assailants and found herself badly injured in the intensive care unit of the local hospital. Moreover, in the rank and file of organisational life, women were at the heart of the informal networks that characterised the squatter invasions in the late 1980s and 1990s. As Makhathini (1992: 6) has shown, women household heads left one part of the family in one shack while other members move on to new land 'to establish further colonies for the rest of the family'. For the vast majority of women, as the settlement stabilised, these same informal networks became loosely organised social or self-help groups such as savings clubs, burial societies and church groups. It was these networks that the CMDA was keen to reach and build upon.

Their way was blocked in part by the fact that community politics were highly politicised. Cato Manor covers two wards, one embracing the former African township of Chesterville, which was incorporated into the project area and the other, the newer squatter areas occupied from the late 1980s onwards. There was inevitable friction between the two as people in the established ward resented resources going to the informal settlements, when they had suffered deteriorating conditions and chronic overcrowding in apartheid housing that dated back 50 years. In this context it is not surprising that participation was relatively shallow in the beginning, simply involving consultation about particular projects through the Cato Manor Community Organisation (CMCO), an umbrella body with representatives from existing civic organisations. Later on Development Committees (DCs) were formed, at which point the focus shifted towards community development and working with less formal structures. This enhanced the involvement not only of women, but of ordinary women. It was usually women who engaged in the hard graft of the DCs and picking up on this, the CMDA organised meetings to facilitate women. They were held in the early evenings so people could attend after work and could walk to them in daylight. Afterwards they were transported home. Nevertheless, women made huge sacrifices to attend 
and often in community meetings pushed men forward to take leadership positions, for example in the CMDO where they were more in evidence.

CMDA staff complained that participatory processes were difficult because every issue became deeply politicised and because structures became entangled with factional struggles within political parties. It was felt by some that the practice of working through DCs was limiting and that information did not filter down to a broad range of residents. For example, the CMDA wanted to bring in representatives of a broader range of groups active in the area such as community health workers doing home-based care for HIV/AIDS and TB patients, groups of women doing craft work together, school leavers without employment, those engaged in income-generating activities and women's church organisations. There was strong resistance to this from the male and female leadership and so the CMDA responded by developing alternative communication strategies designed to reach community members directly. One example was a community newspaper, Izwi ('The Voice'). Another strategy was mass meetings where attendees were predominantly women who were otherwise excluded from access to information and decision making.

While the significant degree of overlap between the various forums led to problems of gate keeping, it did lead to a filtering of awareness about gender issues within Cato Manor, with the emphasis coming largely from women in the ANC local structures, who in turn influenced deliberations in the $\mathrm{CMCO}$ and its negotiations with the CMDA. The male ward councillor who was deeply rooted in local ANC politics was not allowed to ignore gender issues. The woman ward councillor, who was also closely linked to ANC structures, chose to place strong emphasis on the Party's commitment to gender equity, fighting openly for the women in her constituency through her position on the CMDA's Board and in the community. Interestingly, some claimed that even when men were in leadership positions, women still dominated politics and negotiations in the area.

\section{Conclusions}

We have shown the importance of the national policy environment and the political moment for strengthening women in Cato Manor to hold the CMDP to account on gender issues. This rendered the project gender sensitive in spite of the absence of project documents calling for headcounts of women's involvement and gender headlines in monitoring and evaluation. Indeed, the first clear mention of gender in project documents came with the terms of reference for the mid-term review (European Union 2000: A1-9). While the CMDA had few problems reporting on the involvement of women and a number of gender issues, it found it difficult to fully comply because there was so little gender analysis across the life of the project and no gender disaggregated baseline data to draw on. In a common trend, the flurry to get projects approved and underway meant that social analysis was neglected and gender analysis along with it.

Within the project team, there was a significant strong feminist consciousness among several CMDA staff members keen to promote women's strategic interests through the project, including women's property rights and issues of women's public health and safety. Among the staff more generally, an awareness of gender issues emerged as well from a more generalised commitment to social justice. Many of the urban sector specialists involved in the CMDP came from progressive NGOs involved in anti-apartheid struggles. However, without a feminist perspective and under pressures of delivery, their approach swiftly became instrumentalist, with women seen as the core and the more reliable partners of the community. Hence, the level of gender practice varied quite widely within the CMDA, with different staff members seeing it as more or less central to their work.

That there was this variation among staff and change over time derived from the management style within the CMDA. While decidedly outcome driven, it was also flexible and sensitive to process, when this did not compromise the bottom line. A reluctance to impose frameworks and analysis from the top and a preference for letting issues bubble up from below, allowed room for manoeuvre among gender advocates within the organisation and strategic influence on the part of community partners.

Ultimately, it was politicised women within Cato Manor itself who ensured that gender equity and women's interests were advanced - women with a history in the national liberation movement and progressive gender politics. This conclusion supports the view that women's involvement in development is essentially a political project and that without it, the more technical project of gender 
mainstreaming is a rather blunt instrument (Beall 1998). This is not to let development practitioners off the hook. It was strong social justice and gender advocates within the CMDA who opened up spaces for gender issues and women's interests to be put on the agenda. As one woman leader on the CMDO explained, 'in Cato Manor the women have taken the opportunity and opened the door'.

The counterfactual question remains as to whether if implemented elsewhere, tabula rasa, the same outcome would have arisen. This we cannot know and we did not have the opportunity to undertake comparative work at the time. With the proliferation of similar projects in Durban emerging in the wake of Cato Manor and in a period following the first flush of democracy, the opportunity for future comparisons might arise. We would argue on the basis of evidence from Cato Manor, for the importance of history and women within it. The women active in the resettlement and development of Cato Manor were able to draw on the knowledge of women who challenged apartheid in the past and indeed, their memory was held aloft as a badge of pride and example to be followed by women activists in the area.

However, the forces of history are not always predictable and the scars of apartheid, poverty and decades of insecurity left their mark on the exercise of agency in unexpected ways. The response of people in Cato Manor to the opportunities of

\section{Note}

* This article draws from a study of gender within the CMDP (Beall, Todes and Maxwell 2002) commissioned by the CMDA as part of a broader documentation of the project and assessment of experience. We are grateful to the project for permission to publish independently from this study. J.B. acknowledges support from the School of Development Studies at University of KwaZulu-Natal where she holds a visiting professorship. development were also embedded in violent conflict and patterns of patronage associated with the struggle for emerging resources. Women were at the heart of this fray, with access to housing and other resources being achieved on the basis of strident tactics on the part of the leadership. Clearly in projects where real resources are on offer, efforts towards gender equity do not escape the dilemmas of delivery that dog any pro-poor distributive initiative, offering salient lessons against essentialist arguments.

In spite of these provisos, the achievements for women in Cato Manor made over the last ten years have been remarkable. It is too early to tell whether the gains will be sustainable. It is up to future studies to determine, for example, whether women will come to benefit more from local economic development or will hold on to their hard won houses. The task of future researchers would certainly have been made easier by gender disaggregated data, emanating from a gender focus in the project from the outset. It is also too early to tell whether the gender "head-space" created by the political moment, progressive policy and engaged local politics will be retained in Cato Manor or filtered into future projects. What is clear is that integrating gender into project development is more likely to arise from the experience and indeed the political experience of practitioners and partners, than from project "headlines" and "headcounts".

1. This is a name adopted by the gangs evoking MK, the short name given to Umkhonto we Sizwe, the armed wing of the ANC. 


\section{References}

Beall, J., 1998, 'Trickle down or rising tide? Lessons on mainstreaming gender policy from Colombia and South Africa', Social Policy and Administration, Vol 32 No 5: 513-34

Beall, J., Todes, A. and Maxwell, H., 2002, 'Gender and urban development in Cato Manor', paper presented to the Urban Reconstruction and Cato Manor Conference, Cato Manor Development Association, Durban

Edwards, I., 1996, 'Cato Manor, June 1959: Men, Women, Crowds, Violence, Politics and History', in P. Maylam and I. Edwards (eds), The People's City: African Life in 20th Century Durban, Pietermaritzburg: University of Natal Press

European Union, 2000, Mid-Term Review Report: Cato Manor Development Programme, Durban: European Union, Durban Metropolitan Municipality and Cato Manor Development Agency

Goetz, A.M., 1997, 'Introduction: Getting Institutions Right for Women', in A.M. Goetz (ed.), Getting Institutions Right for Women in Development, London: Zed Books: 1-30

Hindson, D. and Byerley, M., 1993, 'Class, race and settlement in Cato Manor: a report on surveys of African and Indian households in Cato Manor - 1992', unpublished manuscript

Hindson, D., Foster, C. and Eising, W., 2002, 'Social entrepreneurship in a low-income township', Report to the Cato Manor Development Association, Durban

Jackson, C. and Pearson, R. (eds), 1998, Feminist Visions of Development: Gender Analysis and Policy, New York and London: Routledge
Jahan, R., 1995, The Elusive Agenda: Mainstreaming Women in Development, London: Zed Books

Kabeer, N., 1994, Reversed Realities: Gender Hierarchies in Development Thought, London: Verso

Levy, C., 1996, 'The process of institutionalising gender in policy and planning: the "web" of institutionalisation', DPU Working Paper 74, London: Development Planning Unit, University College London

Makhathini, M., 1992, 'Squatting dynamics: a look from within Cato Manor', unpublished manuscript

Makhathini, M. and Xaba, T., 1995, 'A report on the socio-economic survey of the informal area of Cato Crest in Cato Manor', unpublished manuscript

Maylam, P., 1996, 'The Struggle for Space in Twentieth-century Durban', in P. Maylam and I. Edwards (eds), The People's City: African Life in 20th Century Durban, Pietermaritzburg: University of Natal Press: 1-30

Moser, C., 1993, Gender Planning and Development: Theory, Practice and Training, London: Routledge Moser, C., 1987, 'Women, Human Settlements and Housing: A Conceptual Framework for Analysis and Policy making', in C. Moser and L. Peake (eds), Women, Housing and Human Settlements, London: Tavistock

Petersen, I., Bhagwanjee, A. and Mzimela, F., 2003, 'Urban regeneration in the era of HIV/AIDS: the case of Cato Manor', paper presented to the Urban Reconstruction and Cato Manor Conference, Cato Manor Development Association, Durban 